\section{G153(P) STRATEGY DISCUSSION INVITATIONS TO COMMUNITY PAEDIATRICS - A MARKER OF THE HEALTH OF INTERAGENCY WORKING?}

A Burton, I Smith, A Lorek. Community Child Health, Evelina London, Guy's and St Thomas' NHS Foundation Trust, London, UK

\subsection{6/archdischild-2018-rcpch.149}

Aim To analyse trends and any link between child protection medical assessments (CPMA) and strategy discussion invitations (SDI) within a community paediatric service.

Background Working Together to Safeguard Children ${ }^{1}$ states that, "whenever there is reasonable cause to suspect a child is suffering or is likely to suffer from harm,' there should be a strategy discussion to share information and formulate a plan to safeguard the child with minimum attendees including a health representative. ${ }^{1}$

Method The number of non-accidental injury (NAI), child sexual abuse (CSA) and total CPMA and SDI in an inner London borough were collected from 2010 to 2017. Spearman's Rank Correlation was applied to NAI, CSA and total data to investigate any link between numbers of CPMA and SDI.

Results CPMA reduced from 212 to 144 (by 32\%) and SDI from 204 to 31 (by 84.8\%) despite the same criteria for assessment and attendance. Spearman's Rank Correlation coefficient for NAI CPMA/SDI was 0.5 ; a moderate correlation. The coefficient for both CSA and total CPMA/SDI was 0.84; very strong correlations.

Conclusions The Munro Review of Child Protection emphasised that, 'coordination and communication between professionals and agencies is crucial to success, ${ }^{2}$ in safeguarding children.

A decrease in strategy discussions may be multifactorial, including the development of HAVEN provision, but community paediatric discussion is important in ensuring optimal information sharing.

A decline in the number of CPMA and SDI may reflect barriers in communication between agencies and this data has supported interagency training.

The additional finding of a strong correlation between CPMA and SDI may not be causal but reflects general barriers in communication between Children's Social Care and Community Paediatrics.

Both the decline in CPMA and SDI as well as the correlation in the trends, merit further evaluation locally and may be relevant for other child protection services.

\section{REFERENCES}

1. Working Together to Safeguard Children. A quide to interagency working to safeguard and promote the welfare of children March 2015. https://www.gov.uk/government/uploads/system/uploads/attachment_data/file/592101/Working_Together_to_Safeguard_Children_20170213.pdf [Accessed: 17/10/2017].

2. Munroe E. Munro review of child protection: Final report. A Child-centred system May 2011. https:/www.gov.uk/government/uploads/system/uploads/attachment_data/file/175391/Munro-Review.pdf [Accessed: 17/10/2017]

\section{G154(P) HOW TO TEACH PAEDIATRIC SAFEGUARDING TO TRAINEE PHYSICIAN ASSOCIATES}

NL Daniels. Community Child Health, Wirral UniversitTeaching Hospitals NHS Trust, Wirral, Merseyside, UK

10.1136/archdischild-2018-rcpch. 150
Introduction Physician Associates (PA's) are becoming an important part of the healthcare professional workforce. They are exposed to paediatric patients in primary and secondary care, and need to have a working knowledge of recognising suspected non-accidental injury, and the appropriate steps to take in managing these children. It is a core competency in their training. There is no guidance in place to assist in achieving this competency or ensure they are adequately trained in this area. Formal training was developed to rectify this.

Aims To effectively teach safeguarding principles in children to PA's. To ensure PA's are confident in recognising non accidental injury as a possible diagnosis. To teach the management of any suspect NAI, including the safeguarding referral process. Methods Interactive learning session through case explanations, group discussion and guidance.

Results Good engagement in session and learning objectives achieved.

Conclusions Serious case reviews and specific examples of injuries generated interactive discussions and provided a practical application to safeguarding guidance and legal frameworks: students acknowledged the relevance and importance of training, including responding if they suspect NAI and other safeguarding concerns. PA training needs to develop to ensure consistency of child protection teaching and include all forms of abuse and not NAI specific.

\section{G155(P) MORE THAN A BREAK: THE IMPACT OF CHANGING LOCAL SKELETAL SURVEY POLICY}

H Jacob, R Hewitson, G Hann. Department of Paediatrics, North Middlesex University Hospital, London, UK

\subsection{6/archdischild-2018-rcpch.151}

Aims Given variations in practice, Wood et al. (2014) proposed criteria for undertaking a skeletal survey in children under two presenting with a fracture.

We incorporated these criteria into our local hospital policy for performing skeletal survey. This study aimed to establish the impact of the new guidelines on the number of skeletal surveys performed and the yield of occult fractures.

Methods We conducted a retrospective casenote review over two consecutive years: the year before the change in the skeletal survey guideline and the year following its implementation. We reviewed the electronic records of all children under two presenting to the Emergency Department with a fracture and cross-checked this with all skeletal surveys performed in this age group. Those with finger or toe fractures were excluded.

We recorded the child's age, the mechanism proposed and any delay in presentation. We noted the fracture type and whether a skeletal survey was, or should have been, performed. Any additional fractures were recorded. All records were reviewed by two researchers.

Results There were 108 records included: 64 before the policy change and 44 after. The children's mean age was 16 months (range 3 weeks to 23 months).

Before the policy change, $5 / 64(8 \%)$ children underwent skeletal survey and 13/44 (30\%) afterwards. There was 1/64 (2\%) additional fractures identified prior to the change and $3 / 44$ (7\%) afterwards. There were four children before the policy 